\title{
Study on Learners' Demotivation in EFL Classroom - A Case Study at a Higher Vocational College
}

\author{
Can Chen \\ Department of Foreign Languages, Wenzheng College of Soochow University, Suzhou, People's Republic of China \\ Email address: \\ WZJ066@suda.edu.cn \\ To cite this article: \\ Can Chen. Study on Learners' Demotivation in EFL Classroom - A Case Study at a Higher Vocational College. Education Journal. \\ Vol. 8, No. 6, 2019, pp. 338-343. doi: 10.11648/j.edu.20190806.25
}

Received: November 3, 2019; Accepted: November 22, 2019; Published: December 3, 2019

\begin{abstract}
Motivation plays a significant role in second language acquisition and teaching. Though it has been studied for decades both by practitioners and researchers, the author still finds that the major research centers on studying motivation of learning and acquiring the language, particularly, the English; while ignoring another opposite perspective: demotivation of language learning. Based on the literature review, the investigation on demotivation factors started very late both at home and abroad in academia thus producing few achievements so far. Due to this research gap, the writer thinks that the study on demotivation of L2 learning and acquisition should be expanded further. Therefore, this paper explores the demotivation factors on learning English among students from vocational education sector by interviewing nine participants from a higher vocational college in Suzhou Industrial Park, Suzhou City, Jiangsu Province in the People's Republic of China. Through analyzing their responses and learning situations via questionnaires and semi-structured interviews, the author concludes that teachers' factors on learners' demotivation are decreasing while issues including lack of learning strategies, lower learning aptitude, previous unpleasant learning experience, and out-of-dated textbooks are turning to be the main causes for students' demotivation in learning English in the context of higher vocational education. At last, the writer proposes some coping strategies for teaching practice, such as building up students' self-confidence and innovating the current textbook, etc. Moreover, the relevant studies in various contexts should be conducted in the future for enriching the existing literature and giving inspiration to teaching practitioners.
\end{abstract}

Keywords: Demotivation, Higher Vocational College, EFL Learning, Vocational Education

\section{Introduction}

Motivation plays an important role in second language acquisition; practitioners are often adopting various teaching methods for motivating students' interests and changing classroom activities constantly to maintain learners' interest in L2 learning. Therefore, motivation, as a crucial individual difference in L2 acquisition, has been studied for several decades.

Theories on L2 motivation have gone through mainly four stages from socio-psychological to cognitive-situated period and process-oriented to socio-dynamic perspective; the underlining implications of motivation studies give copious enlightenment both for teachers and students. However, motivation is not a stable state and often undergoes dramatic changes, it is common for teachers to find that students usually lose their motivation gradually in L2 learning, which brings difficulties and challenges both for teaching and learning. The gradual loss of learners' motivation has been labeled as "demotivation" in second language acquisition.

In the 1990s, foreign researchers have begun to investigate learners' demotivation of studying foreign languages and there has been much achievement so far. By comparison, domestic studies in Chinese ELT context start very late and focus on students in prestigious universities. But demotivation in L2 learning happens among learners from universities at various levels, since English proficiency appears to be very important and serves as the gatekeeper in job-hunting and continuous education, learning English well is equally important for all. Therefore, studies on demotivation in L2 learning should be expanded to a broader framework and involve in more demotivated learners with diversified backgrounds.

This paper attempts to investigate learner's demotivation 
factors in higher vocational colleges by a case study with several demotivated learners from a higher vocational college in Suzhou Industrial Park of Jiangsu Province, the People's Republic of China. The aim of the study is to enrich current findings on demotivation of Chinese English learners and contribute some strategies in coping with students' demotivation for teachers.

\section{Literature Review}

"Demotivation, concerns various negative influences that cancel out existing motivation" and the 'demotivated' learner is described as someone who once was motivated but has lost his or her interest or commitment for some reasons.[2]For distinguishing demotivation with others motivation deficiency caused by negative factors, they emphasize the demotivation concerns "specific external factors that reduce or diminish the motivational basis of a behavioral intention or an ongoing action". [2] Research on demotivation commences with the study in instructional communication and two factors were identified to be influential on students' demotivation: (1) behaviors of teachers; (2) structure and format of course design. One researcher implemented the content analysis among 250 American students by requiring them to write essays describing conflicts with teachers and uncomfortable classrooms in past five years' learning experience. This study on L2 demotivation of students attributes the major negative influences on teachers' behaviors and attitudes, which is consonant with the previous findings. Before that, the demotivational factors of students have been investigated by administering a questionnaire to 191 primary students and seven teachers in Leeds, United Kingdom. Teachers perceived the reasons for demotivation to various factors such as psychology, attitude, society, history and geography but excluding themselves. However, students' responses were not confined to the teachers anymore; complaints on the large group scale and the poor learning environment were mentioned. According to the qualitative investigation of Ushioda, participants reported that learning contexts, such as teaching methods and learning tasks were the causes of demotivation in L2 learning experience. [2]

Concerning the research on demotivation of L2 learning, communication and cooperation with students has been emphasized and it is asserted that students' ideas and opinions are of great significance for researchers, they must address some teacher-and course-related aspects addressed by students if they want to re-motivate students in L2 learning. Based on the previous experience, Dörnyei (1998) completed a study on demotivation via the close collaboration with students. The research of differed from previous studies [2], it directly paid special attention to demotivated learners instead of inquiring with general students on their unpleasant learning experiences. The researcher had the one-to-one interview with 50 secondary students from different schools in Budapest; these students have been identified by teachers or peers as particularly demotivated learners in foreign languages (English and Germany). The main demotivating factors can be classified into 9 categories and have been summarized by Dörnyei as teacher factor, inadequate school facilities, reduced self-confidence, negative attitude towards the L2, compulsory nature of L2 study, interference of another foreign language, negative attitudes towards the L2 community, attitudes of group members and teaching materials.

From that time, attention on demotivation study has been shifted from subjective perspective (e.g. teachers and students, etc.) to objective perspective (e.g. school environment, attitudes to L2 and the community, influences of group members, etc.).

In the 21st century, Dörnyei's study in 1998 had aroused the huge interest of researchers in Japan where demotivation among English learners appears to be a major concern in education. Falout and Maruyama (2004) focused on the relationship between demotivation and learner's proficiency, which indicate that lower proficiency learners preferred to owe demotivation to internal factors such as decreased self-confidence and disappointed achievement while higher proficiency learners were more likely to appeal to external factors such as teachers. Moreover, learners in low proficiency would report demotivating experiences earlier than those in high proficiency.

Certain study reveals that Japanese education system prevents the development of communication skills of students and demotivates their enthusiasm in learning English. In recent years, scholars in Asia (South Korea, Thailand, Iran and Taiwan in People's Republic of China) have emerged in studying demotivation among different groups of learners. The relationship between past demotivating factors of EFL students in technological institute and their English language proficiency has been investigated.[3]The demotivational factors in English learning among elderly learners has been explored in a lifelong education institution in Seoul, South Korea and reveals the correlation between L2 self and demotivational factors.

In Chinese ELT context, a great number of studies are about positive factors such as students' motivation and learning strategies in L2 acquisition but ignoring the negative factors like demotivation. [5, 14] Therefore, demotivation studies on Chinese English learners started late and have few achievements. 270 undergraduates from one of the universities in Anhui Province have been investigated and confirmed that the main factors causing students' demotivation are from teachers, so teachers should adopt some strategies to curb the demotivation and strengthen motivation. [10] The concept of "motive deficiency" has been introduced through reviewing past studies of foreign scholars, stimulating interests of domestic researchers and calling for more studies on demotivation.[11] A causal model of demotivation in English learning has been constructed by means of interviews and questionnaires among demotivated students [4], putting forward several factors can result in 
demotivation such as environment, valence, purposes, interests and anxiety.

After reflecting on previous studies on demotivation, 277 non-English major college students were surveyed in Guangdong province. [12] The author claims that teacher is in the dominant role on influencing students, teachers should both improve their language proficiency and teaching skills for initiating and maintaining students' motivation. Some researchers examine three experiments done previously and pointing out they all emphasize teacher's factors but seldom connect to Chinese learners' characteristics on demotivation, such as lack of learning strategies and intrinsic interests. From their investigation of 766 college students in Zhejiang province, they conclude that lack of effective learning strategies is the most critical demotivation factor.[12] The proportion of teacher factors has been reduced drastically comparing to previous experiments, although teachers are still the main causes on learning demotivation. However, one study argues that present studies neglect the correlation between proficiency and demotivation. [13] Being inspired by the study of Falout\&Maruyama, they try to discover the relationship between internal demotivation factors and learners' language proficiency. [7] There are some flaws among the experiment design of existing studies, for example, some of the items in questionnaires are suggestive for participants, the category of learners' motivation is not reasonable. [1] Therefore, they conducted a questionnaire among 85 students in one of the universities in Hunan Province to find out the observable factors on demotivation of students in learning English and first attempt to probe the differences between genders. It is acknowledged that the progress of Chinese studies on demotivation, but he also notes that the research population is limited to some key and time-honored universities in China while some newly established higher education institutions have been ignored. It involves in 713 college students from 5 newly established universities to investigate their demotivation factors as well as the link between demotivation and learning environment.[8]As many researchers said, the future research should investigate students from different education backgrounds for deepening the understanding on demotivation in English learning. [1] Therefore, we may notice that some of the ELT practitioners have had some tentative attempts on studying demotivation factors among other learners' groups, for instance, students in higher vocational colleges. A questionnaire and some interviews have been conducted for generalizing the following demotivating factors among students in higher vocational college: (1) Learning Materials and Tasks; (2) Students' Confidence and Interests; (3) Teachers' Competence and Teaching styles; (5) School Facilities. Then, the research on professional English learning in one vocational college of Shandong province has been specified and concludes eight types of motive deficiency: learners' self-restraint and English capacity, teaching contents and learning environment, teacher and social factors, curriculum design and evaluation methods. [6]
To sum up, research on demotivation of English learning is under-developed and needs further investigation. On the one hand, researchers have limited the research to the fixed framework while ignoring the specific ELT situation; on the other hand, the research population should be expanded to various groups of students with unique features. English teaching and learning in higher vocational colleges has grown to be a significant part in Chinese higher education system, more studies on students from various backgrounds and regions in a larger scale are anticipated.

\section{Research Question \& Methodology}

\subsection{Research Question}

What kind of factors causing demotivation in learning English for students in higher vocational colleges and how do teachers cope with such demotivation in practice?

\subsection{Participants and Context}

Participants in the case study are nine final year students (eight females and 1 male) from a higher vocational college in Suzhou, Jiangsu, the People's Republic of China. They are majoring in Finance, Accounting and Auditing, Property Evaluation and Management respectively in this college. All the students have been studying English for 12 years from Grade 3 in primary school. They were identified by teachers and peers as demotivated students for reasons like lower scores in English exams and inferior performance in English classes (low attendance rate or not engaging in classroom activities). Moreover, 9 students among them did not pass the CET-4(College English Test, Band 4) and one of them scored 454.

\subsection{Instruments}

The research contains a single, qualitative activity with the questionnaire and interview as instruments. The questionnaire has been designed based on the classification of main demotivating factors identified by Dörnyei (1998) and integrated some features of Chinese English learners as well as the specific situations in this college. There are 42 items concerning 10 factors including teachers, classroom environment, learning aptitude, and learning strategies, past unpleasant leaning experiences, textbooks, intrinsic interest, teaching methodologies, external policies and environment, attitudes to L2 and L2 community except for the background information. The questionnaire adopted four-point Likert scales, the numbers 1, 2, 3, 4 represent "very disagree"," disagree", "agree", "very agree" respectively. After filling the questionnaires, each participant has been assigned 5-6 minutes to take a semi-structured interview based on their questionnaires and specify other possible factors causing demotivation in English learning. All the interviews have been recorded and transcribed for ensuring the accuracy of information. 


\section{Findings \& Discussions}

\subsection{Teacher Is Not the Predominant Factor on Students' Demotivation in Learning English}

Being different from previous studies done by researchers in universities, which attribute the principal reasons of students' demotivation to teacher's factors, the study found that teacher's role is not overwhelming to demotivated learners. In an overall view, students are almost satisfied with teachers' English competence; among 9 interviewees, 8 of them agree that English proficiency of teachers is good and only one participant said that "The poor pronunciation of my teacher seriously influence me so that I seemingly lost my learning interest. And sometimes, I think she cannot explain grammar points clearly"

Although all the participants believe that teachers are dedicated to preparing courses and correcting homework on time, some students observe that certain teachers are lack of passion for teaching and seem to be less approachable to students. In addition, some teachers are criticized for being impatient to students and treating them differently. For instance, one of the students said that "My English teacher likes some excellent students and invites them to answer questions in class always. I think I was overlooked so I just play the mobile phone and never listen her classes" Another important reason mentioned by nearly all students is that, they feel uncomfortable about the frequent change of teachers within one semester.

The findings on teachers' influence on demotivation of learners are agreeable with previous studies among higher vocational colleges' students in Guangdong and Shandong [7, 15] but differing from some of the studies based on university students $[1,10,13]$. Some domestic researchers have noted that Chinese students would like to blame themselves rather than criticizing teachers when facing up the failure of learning previously. [1, 16] They attempted to explain the preference from the perspective of Chinese tradition values, that is, Chinese students are under huge influence of Confucius' idea: respecting teachers and valuing education, thus, students in China less attribute demotes to teacher factors as foreign students; however, the author cannot agree with the above explanations, students are in equal position with teachers in today's higher education of China, less attribution to teachers demonstrates that the quality of Chinese ELT teachers has been increasingly improved in the past several years. Most of the teachers working for higher education institutions are well-trained professionals; some of the young talents even possess the master's degree or above in Education, English Linguistics or TESOL (Teaching English to Speakers of Other Languages) and have rich overseas learning experience. Therefore, they all acquire the advanced teaching methods and have sound English proficiency. However, teachers' emotions are easily affected by many factors like environment, attitudes of learners and the interaction with students; therefore, they may inevitably produce some negative behaviors like being impatient to students, treating students indifferently, which result in learners' demotivation. In addition, situations like changing teachers frequently are out of their control, some interviewees complained that "I like the teacher, but she has taught us for one semester only and we got a new teacher next semester, but I do not like the teaching style of the new one......some students even said that "our English teacher has been altered for three times within one semester..." It seems that some problems are caused by management and policy affairs beyond the teachers.

\subsection{Lack of Appropriate Learning Strategies and Low Aptitudes in Learning English}

Almost every participant thinks that lack of proper strategies and low aptitudes in learning English are the fundamental reasons for demotivation. One student said that "Nobody guides us how to learn English well, there is not any teacher guiding us in English learning strategies." Even though some teachers may introduce learning strategies in class, but they may not be suitable for every student. "Teachers often wrongly consider that students have mastered a series of learning strategies after studying English for several years. Some of the strategies introduced by them are not appropriate for all." An interviewee stated.

In addition, relatively lower English proficiency and learning aptitudes make students in higher vocational colleges feel depressed and helpless in learning English. A student lamented: "Memorizing vocabulary and grammar is so difficult for me from high school. But without such knowledge, it is impossible to learn the language well, so I am pretty disappointed about learning English." Another added: "I found my aptitude in learning English is lower than the peers. I was very hard--working in learning English when I was in junior school, my teachers and parents acknowledged my efforts, but the final score was terrible so that my self-confidence has faded."

Therefore, it formed a cycle that students with lower learning aptitude and English proficiency are lack of sufficient guidance on learning strategies. With the increasing difficulty of learning contents, it will be harder for them to understand the course, not to mention actively participating classroom interaction. Finally, they lost their interest in learning English and turned to be a demotivated learner.

\subsection{The Large Scale of Class and the Incomprehensible Textbooks}

Demotivation in learning English is also connected to class scale and learning materials.

Almost everyone feels unsatisfied with having English classes with more than 50 people in one large classroom. "The class size is too big so that we hardly have chances to communicate in English...It is a super-huge class with nearly 100 students in one classroom, and students from three different classes are having English classes together, we even do not know the name of the teacher." 
With the expansion of Chinese higher education, not only the universities recruit excessive students every year, the same thing happens in vocational colleges. It leads to an imbalance of proportion of students and teachers. The policy makers and leadership would like to create more chances for students to learn major-related knowledge or do work placement internship while neglecting the importance of English. Therefore, the public compulsory courses like English have been squeezed and put in a very embarrassing place. Just like a student described: "We only have eight weeks in Year 3 and eight English classes for each week. It takes us half day to sit still and listen to the same teacher for continuous three hours."

Problems on the textbooks are also the source of demotivation. Some students are bored with the textbooks. "They are old-fashioned and boring. The after-class exercises in every unit are in the same format." The other may think that contents in textbooks are not practical for future career, "We are not English majors, but the current textbook presents abundant vocabulary and grammar beyond us. Learning some oral English will be beneficial for our work"

As students stated, current-used textbooks and learning materials are too difficult to understand. For instance, the course English for Career contains some ESP (English for Specific Purposes), which is hard for students in lower English level to comprehend. Besides that, students commonly think that skills in textbooks are seldom used in real life; one interviewee said that "Taking meeting minutes is good but I do not think it will be helpful for me. It is designed for the staff working for foreign-owned companies, but it is almost impossible for us (students in vocational colleges) to work for such enterprises." So, it is necessary for course and material designer to take learners' needs into consideration and teachers can do some appropriate adaptations in practice.

\subsection{Intrinsic Interest and External Environment}

Prior to the survey and interview, the researcher hypothesized that demotivation of students in higher vocational colleges is originated from school policies and external environment since certain students ever said that English scores do not have any influence on the application for scholarships so no one will value English subject. However, the research shows that more than $90 \%$ of interviewees denied about this and think that learning English is still useful and meaningful regardless of school policies. But, a large number of students are in an ambivalent position when talking about the intrinsic interests of learning English. Most of them are in the dilemma of learning English or not, they think that whether they can use English as a communication tool is hugely depending on their workplaces.

"It is very hard for me to answer whether the English is important or not. If I work in Suzhou, it is super-important to learn English well since there are many foreigners here. But my parents want me to work in hometown, a small county in northern part of Jiangsu province. If I work in that place, there is no necessity to learn English since I will not use it."
A female student said.

\subsection{Other Factors on Students' Demotivation of English Learning}

There are some other reasons for students' demotivation in learning English which may not the typical causes for learners' demotivation, but they are worth of considering because effective and efficient ELT classroom needs the attention and participation of every student.

First, almost all the students show their interest in L2 and L2 community, only one interviewee dislikes the English language. It is pleased for teachers to know about the fact that quite a number of students do not lose the interest of the language, thought they are suffering in learning it. Second, classroom conditions appear to be the least influential factor to English learning. In the past decade, the education department of China has made great efforts to modernize classroom equipment to realize that each of the classrooms in colleges is well-equipped with projector, laptop and air-conditioner to make the environment better. Teachers frequently use modern technology such as presentation slides, videos as their teaching instruments. However, there is a concern about some teachers are over-dependent to modern teaching devices while overlooking basic skills of teachers. A student depicted that "One of my teachers relies on laptop extremely, when she thinks something is necessary for taking notes, she types some words on Word instead of writing on blackboards."

\section{Implications for EFL Teaching and Learning Practices}

\subsection{Rebuilding the Self-Confidence of Learning English}

A great majority of students in higher vocational colleges are with lower English proficiency and learning aptitude, therefore, they appear to lack of enough confidence in learning English well, some students may even suffer from the past failure learning experiences. It requires teachers not only to instruct English language but also help students to re-construct their own ideal-self, ought-to self. Moreover, teachers should keep an eye on development of students and help them to overcome the difficulties in learning English.

\subsection{Calling for Innovation of Textbooks and Learning Materials}

It is suggested that current textbooks and learning materials are beyond the proficiency of students. Therefore, it is urgent to call for the innovation of textbooks and learning materials. In addition, teacher learns how to personalize and localize the materials for meeting the needs of students. It requires practitioners not to rely on textbooks solely but to adopt the available sources for better serving learners' needs. For example, taking newspapers, advertisements, audios and videos from television as instructional materials. 


\subsection{Introducing Effective Learning Strategies to Students}

Instructing effective strategies in learning should be part of the English teaching. The study shows that the absence of effective learning strategies is the main cause for demotivation. Teachers should not only focus on instruction of language but also introducing effective strategies and methods in learning English well. A routine needs analysis among students should be conducted via questionnaire and interview to understand students' learning needs on time for providing them with feedback and updated learning strategies.

\section{Conclusions}

This paper attempts to investigate the demotivation factors of students in higher vocational colleges through a case study contains the questionnaire and semi-structured interview with nine participants. It reveals that interviewees prefer to attribute the demotivation to internal factors like lower L2 learning aptitude, damaged self-confidence because of unpleasant learning experience before and lack of effective learning strategies in L2 instead of the external factors such as teachers and the environment.

The study demonstrates that students' perceptions on demotivation in English learning have been changed. Compared with the previous findings of empirical studies, the causes for students' demotivation of learning English not only focus on the external factors like environment and the teachers but also link with their learning strategies and experience. In addition, the adaptation and update of the current textbooks are worthy of our attention. Therefore, researchers and ELT practitioners should ponder the problem of demotivation from different facets in the future for understanding the underpinning demotivation factors of the students and proposing according solutions for that.

However, since the study is limited to a small-scale experiment with few students in the same college, the larger scale of discovery involves more participants from different schools are expected.

\section{Acknowledgements}

This research was sponsored by 2019 Jiangsu Provincial Education Bureau Philosophy and Social Sciences Research Funding Program (No.2019SJA2122).

\section{References}

[1] Cai Jinwen \& Hou Xianrong. A Study on Demotivation of College EFL Learning, English Teachers, No. 7, 2013, pp. 14-22.
[2] Dörnyei, Z. \& Ushioda, E. (2011). Teaching and Researching Motivation. (2nd Edition) Harlow, England: Pearson Education.

[3] Hu, R. J. The Relationship between Demotivation and EFL Learners' English Language Proficiency, English Language Teaching, No. 4, 2011, pp. 88-96.

[4] Hu Weixing \& Cai Jinting. Constructing the Model of English Learning Demotivation, Foreign Language Education, No. 21, 2010, pp. 41-49.

[5] Hua Huifang. Study on English Learning Motivation and Strategies, Foreign Language World, No. 71, 1998, pp. 44-79.

[6] Kan Zhiwen \&Sun Wenjing. An Analysis of Motive Deficiency in Students' Professional English Learning, Guangzhou Vocational Education Forum, No. 12, 2013, pp. 31-36.

[7] Kim, T. Y. \& K., Y. K. Elderly Korean Learners' Participation in English Learning through Lifelong Education: Focusing on Motivation and Demotivation, Education Gerontology, No. 41, 2015, pp. 120-135.

[8] Li Chili. An Analysis on Demotivation Factors of College Students EFL Learning, College English, No. 11, 2014, pp. 86-94.

[9] Li Lin. A Study on Internal Factors of Chinese College EFL Learners' Demotivation, JOURNAL of PLA University of Foreign Languages, No. 36, 2013, pp. 65-69.

[10] Liang Liang. Study of demotivation in English classroom, Journal of Tianjin University of Technology and Education, No. 18,2008 , pp. $75-78$.

[11] Tang Wenli. Status, Trend, Enlightment of the Overseas Research "Motive Deficiency", Journal of Guangdong Polytechnic Normal University, No. 5, 2009, pp. 89-92.

[12] Tang Wenli. An Analysis of Demotivation on Non-English Major College Students, Foreign Language Education, No. 33, 2012, pp. 70-75.

[13] Wang Jun \&Zhou Lele. Study on learners' demotivators in graded English teaching in universities, Journal of Changchun Institution of Technology (Social Science Edition), No. 13, 2012. pp. 107-109.

[14] Wen Qiufang. Rules and Characteristic on the Change of Motivation Concepts and Strategies for English Leaners Foreign Language Teaching and Research, No. 33, 2001, pp. 105-110.

[15] Zhang Xiuqing \&Zhang Jianfang. The study of demotivating factors of English learning in higher vocational colleges, Journal of Hubei Normal University (Philosophy and Social Science), No. 32, 2012, pp. 124-127.

[16] Zhou Cibo \& Wang Wenbing. Demotivators Analysis of Chinese University EFL Learners, Foreign Languages in China, No. 9, 2012, pp. 48-55. 